\title{
Trophic restructuring of coral reef fish communities in a large marine reserve
}

\author{
Robert W. Lamb ${ }^{1,2, *}$, Darren W. Johnson ${ }^{1}$ \\ ${ }^{1}$ Department of Zoology, Oregon State University, Corvallis, Oregon 97331, USA \\ ${ }^{2}$ Present address: Maestría en Ecología, Universidad San Francisco de Quito Diego de Robles y Vía Interoceánica, \\ Cumbayá, Ecuador
}

\begin{abstract}
Marine reserves can directly replenish heavily fished species. However, communitywide effects of reserves are less clear. Marine reserves directly reduce fishing mortality rates, but through the restoration of apex predators, reserves may have strong indirect effects on non-target species. We explored the effects of a large, fully protected marine reserve in the Bahamas on the community of coral-reef fishes. We examined the effect of the reserve on fish biomass by comparing the density and size of all fishes on similar reefs located inside and outside the reserve. Total biomass of fishes was approximately $7 \times$ higher in reserve sites, where biomass was strongly concentrated in species of higher trophic levels. Analysis based on the relative magnitude of individual species' responses indicated that, on average, the largest species increased in biomass within the reserve, intermediate-sized species decreased, and the smallest species exhibited variable responses. Species' responses to the reserve were also examined by pooling species into 9 trophic categories using consumptive relationships, which provided corroborating results. Large piscivores (e.g. sharks, large groupers) were on average larger and more abundant inside the reserve. Mid-trophic-level groups (e.g. small piscivores) had higher average biomass outside of the reserve, where the number of species and biomass of large predators was lower. Finally, some low-trophic-level groups (e.g. planktivores) had higher biomass within the reserve, while others (e.g. small herbivores) did not respond strongly. Overall, these results suggest that marine reserves can substantially alter the composition and structure of reef fish communities.
\end{abstract}

KEY WORDS: Top-down effects - Indirect effects · Food web - Community structure · Coral reef fishes $\cdot$ Fish biomass $\cdot$ Reef-fish communities $\cdot$ Marine reserve

\section{INTRODUCTION}

Marine reserves can provide spatial refuges from fishing for commercially important species, resulting in higher abundances and larger individuals inside the reserve compared to outside (Sluka et al. 1997, Friedlander \& DeMartini 2002, Halpern 2003). Such protection potentially has significant impacts on the structure of local fish assemblages, because the replenishment of large, top-trophic-level fishery species can affect the relative abundances of other species of fish through species interactions such as competition or predation (McClanahan \& Nyawira 1988). Large marine reserves that have been protected for a sufficiently long time may serve as reference sites to compare to unprotected areas, thereby allowing evaluation of the effects of human activities on living marine resources (Pauly 1995, Sheppard 1995, Dayton et al. 2000).

A large number of comparative studies inside vs. outside of marine reserves have been conducted (reviewed by Côté et al. 2001, Halpern 2003), but most focus on single species or small groups of commercially important species (e.g. Polunin \& Roberts 1993, Wantiez et al. 1997, Chapman \& Kramer 1999, Mumby et al. 2006, 2007). A major challenge for community-wide studies is extracting meaningful patterns in species' responses amid high background levels of variation inherent to diverse assemblages of species. Assessed on an individ- 
ual level, species that are not specifically targeted by fishing tend to exhibit a large degree of variation in their responses to protection by marine reserves (Jennings \& Polunin 1997, Côté et al. 2001, Guidetti \& Sala 2007). Furthermore, habitat characteristics can be a major determinant of species composition within marine communities (Luckhurst \& Luckhurst 1978, Öhman \& Rajasuriya 1998). Differences in habitat characteristics among sites may therefore obfuscate species' responses to reserve protection, making it difficult to detect overall trends within the fish assemblage.

Fishing effort is usually concentrated on large, carnivorous species of the highest trophic levels (Jennings \& Polunin 1997, Steneck 1998), though effort may be redirected down the food web as upper trophic level species decline in abundance (Pauly et al. 1998). Although many coral reef fisheries tend to exploit a wide range of species (McClanahan \& Mangi 2004, CRFM 2005), both fisheries-dependent (Russ \& Alcala 1996) and -independent (Stallings 2009a) studies have shown disproportionate impacts on large-bodied species of higher trophic levels. Depletion of large, toptrophic-level species may be the result of selective fishing over long time scales (Jackson et al. 2001) and/or the tendency for such species to have a low capacity for population growth and resilience to fishing because of life history constraints (e.g. long generation times). In the Caribbean, heavily affected species include sharks (mostly of the family Charcharhinidae), jacks (Carangidae), and grouper (Serranidae), including the Nassau grouper Epinephelus striatus (Parrish 1987). As large piscivorous fish are removed, their prey populations can increase in abundance and size due to release from predation (Frank et al. 2005) and/or competition (Stallings 2008). Fishing intensity often does not decline with decreasing yields (Gordon 1991), which only exacerbates this effect.

Selective fishing may reveal patterns of community structure such as trophic cascades (Pace et al. 1999, Coleman \& Williams 2002). Trophic cascades are characterized by 3 or more trophic levels marked by strong top-down controls, such that an increase in biomass at the upper level causes a decline in the next lower level, which in turn allows an increase in the levels below that and so forth, alternating down the food web (Paine 1980). Therefore, trophic cascades and other top-down processes that alter community structure (e.g. competition) may be revealed by the removal of top-level predatory species and subsequent shifts in patterns of biomass through descending levels of the food web (Power 1990, Strauss 1991). A release from predation may thus lead to changes in the intensity of competition and predation at lower trophic levels, potentially restructuring communities and interactions therein (Carpenter et al. 1985, Carpenter \& Kitchell 1988).
Trophic cascades have been observed in a variety of marine communities (Steneck 1998, Daskalov 2002, Graham et al. 2003, Frank et al. 2005, Mumby et al. 2006, 2007), though the most distinct examples come from relatively simple systems with few trophic levels and low species diversity (Strong 1992, Pinnegar et al. 2000). Indeed, the buffering effects of varied and differentiated consumptive relationships, including omnivory and ontogenetic trophic level shifts, as well as multiple prey refuges, may prevent strong trophic cascades in more speciose systems (Strong 1992). However, Pace et al. (1999) and Frank et al. (2005) highlighted distinct signatures of trophic cascades in moderately complex coastal food webs, suggesting that similar processes may operate in diverse communities such as assemblages of coral reef fishes.

In the present study we examined entire reef fish communities inside and outside of a large, fully protected marine reserve in the Bahamas, testing by comparative observation for evidence of changes in biomass distributions in response to protection. We focused on whether the distribution of biomass within trophic categories varied inside vs. outside of the reserve. We also examined how the effect of the reserve varied by individual species, and, in both cases, whether a signature of a trophic cascade or similar alterations of the reef fish community structure could be discerned.

\section{HYPOTHESES AND PREDICTIONS}

In diverse communities, the exact nature of predatorprey relationships and trophic levels is not always clear. However, for marine fishes, consumption of food types is limited by gape and body size (Wainwright \& Richard 1995, Scharf et al. 2000). Body size correlates well with trophic relationships when viewed on the community level (Jennings et al. 2001), although this trend may deteriorate among smaller species due to the diverse size and morphology seen in the larger species base at this level (Layman et al. 2005). Additionally, body size may be a large determinant of trophic level and ecological role because the outcome of nonlethal interactions (e.g. interspecific competition) may be based on a body size hierarchy (Werner \& Gilliam 1984, Stallings 2008). Combined with a more traditional approach using trophic categories based on trophic scores (i.e. average number of steps up a linear food chain for items found in a species' diet), body size may serve as a good proxy for trophic level and ecological role.

The relationship between species' responses to reserve protection and body size may reveal effects of fishing selectivity as well as effects of trophic 
interactions among species, including trophic cascades. We hypothesized 4 general types of responses that could be observed. First, species' responses may be independent of body size (Fig. 1) and species may be, on average, more (or less) abundant within the reserve. This pattern would suggest uniform effects of fishing on all species rather than concentrated reduction of biomass in higher trophic levels. It would also signify no indirect effect of the reserve on biomass distributions by trophic level. Second, average effects may be positive for species of all sizes, but larger species may be afforded greater protection within the reserve (Fig. 1). Again, this pattern would indicate no indirect effect of the reserve on biomass distributions by trophic level. Third, large species may be more abundant and small species less abundant within the reserve (Fig. 1). This pattern would likely indicate a 2-trophic-level interaction, whereby increased abundance of large fish within the reserve drives down the abundance of smaller fish via predation and/or competition. Finally, the relationship between species' size and effect of the reserve could alternate between positive and negative values, indicating a trophic cascade of 3 or more levels (Fig. 1). In Fig. 1, the largest species (and thus those of the highest trophic levels) would be positively affected by the marine reserve. The trendline may then change between positive and negative values of reserve effect depending on species' size, with the number of trophic levels indicated by the number of times that the curve crosses zero (e.g. a 3-level trophic cascade would cross the zero line twice to delineate a positive-negative-positive relationship between reserve effect and species' size; a 4-level cascade would cross the zero line 3 times).

\section{MATERIALS AND METHODS}

Study sites. The Exuma Cays Land and Sea Park (ECLSP) was established in 1958 and closed to all fishing in 1986. Since then, no fishing or destructive activities have been allowed inside the park boundaries. The reserve encompasses an area of $442 \mathrm{~km}^{2}$, and the no-take policy to protect marine life is effectively enforced by regular boat patrols.

We surveyed fish communities on 5 reefs within the reserve and 5 reefs outside of the reserve. Within each treatment (protected or unprotected), 3 sites were sampled on the fore reef, comprising deep, complex coral structures on the outward-facing reef slope, and 2 sites were located in back-reef areas, comprising shallowwater habitats where small coral heads are interspersed with gorgonians, sponges, and sand. Sites inside and outside of the reserve were paired by depth, reef size, and structural similarity to control for the confounding effects of different habitats on fish community structure. Mean depths of sites ranged from 3 to $20 \mathrm{~m}$, covering a wide range of reef habitats. Reef complexity and coral composition were also measured to document habitat similarity among sites. The 5 unprotected sites ( 3 fore-reef and 2 back-reef) were centered around Lee Stocking Island, which lies roughly $70 \mathrm{~km}$ to the south of the reserve. Reefs near Lee Stocking Island are similar to those within the ECLSP and have been used as comparable reference sites for the ECLSP in previous studies (e.g. Stoner \& Ray-Culp 2000, Lipcius et al. 2001).

Survey methods. Fish communities were assessed using underwater visual census methods. Six horizontal transects were run at each of the 5 protected and 5 unprotected reefs. Six transects were sufficient to cover virtually the whole contiguous reef at most sites.

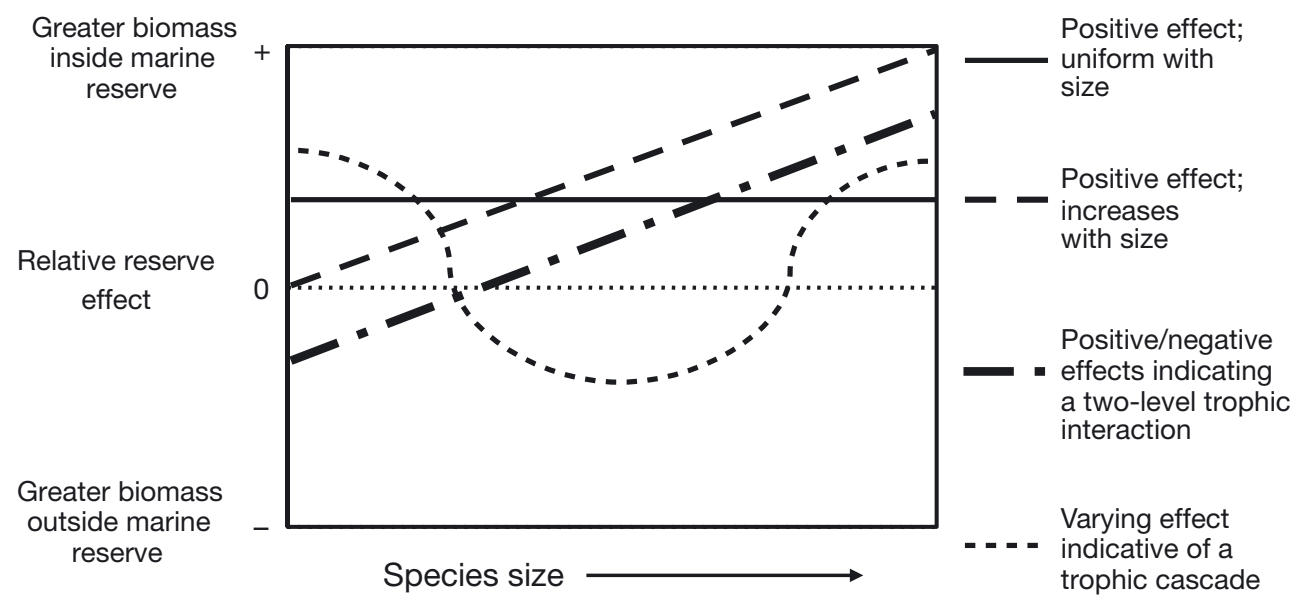

Fig. 1. Alternative predictions of the effects of a marine reserve on the community structure of coral reef fishes based on species mean size as a proxy for trophic level 
Transects were $5 \mathrm{~m}$ wide $\times 25 \mathrm{~m}$ long and encompassed the entire water column from the seafloor to surface. Transects were haphazardly placed within the confines of the reef. During each census, a diver swam over the transect line identifying and counting all fish within $2.5 \mathrm{~m}$ on either side of the central line. Large, mobile species were identified on the first pass as the transect line was laid, then smaller, cryptic species on consecutive passes. For each observation, the diver identified the species and total length (TL) of the fish. Fish lengths were estimated in $1 \mathrm{~cm}$ intervals for fish 0 to $10 \mathrm{~cm} \mathrm{TL}$, and in $5 \mathrm{~cm}$ intervals for fish $>10 \mathrm{~cm}$ TL. Two divers highly trained in census methods performed all transects inside and outside of the reserve. Therefore, any observer bias was equivalent across all transects, enabling meaningful comparisons between protected and unprotected sites.

Reserve effects on species biomass. All fish lengths were converted to biomass using length-weight conversion equations for each species (Bohnsack \& Harper 1988). We used biomass as a metric for reserve effect in keeping with previous studies (e.g. Newman et al. 2006, Kramer \& Heck 2007), and in order to combine the effects of changes in abundances and size into a single value. The effect of the reserve on each species was calculated by comparing biomass measurements $\left(\mathrm{g} \mathrm{m}^{-2}\right)$ between paired protected and unprotected reef sites. Although conducting paired comparisons between similar reefs inside and outside of the reserve controlled for much of the variation in habitat, we also measured several habitat attributes to account for finescale differences in habitat features within reef pairings. Specifically, we measured rugosity and coral cover every $5 \mathrm{~m}$ along each transect. At each point, rugosity was measured within a $0.5 \mathrm{~m}$ radius as the maximum height difference between coral structure and basal substrate. We examined 'average relief' (mean values per transect of rugosity within coral structures) to compare overall structural complexity of habitats among sites. We also examined 'maximum relief' (mean values per transect of maximum relief of coral structures) to compare abundances of large structures (e.g. large coral heads, pinnacles, and so on) that may also influence species composition at a site (Luckhurst \& Luckhurst 1978, Öhman \& Rajasuriya 1998). Coral cover was measured by an index that compared the relative amounts of hard coral vs. soft substrate (sandy bottom, seagrass, or coral rubble). The index ranged from 1 (if all 5 point-intercept measurements in a transect were soft bottom) to 6 (if all 5 point-intercept measurements in a transect were hard coral). When averaged among point-contacts and transects, the distribution of this metric was approximately normal.

Within each site pairing, we calculated the difference in average relief, maximum relief and coral cover.
Because these measures were related, we conducted a principal components analysis to collapse these measurements into a single metric of differences in habitat complexity within reef pairings. The first principal component explained the overwhelming majority of the variation in habitat differences (93\%), so we used the first principal component scores as a covariate in our calculation of the relative reserve effect for each species. For each species, relative reserve effect was calculated for each site pairing as the natural logarithm of the response ratio (LRR):

$$
\ln \left(\frac{X_{\mathrm{MR}}+0.01}{X_{\mathrm{C}}+0.01}\right)
$$

where $X_{\mathrm{MR}}$ is mean biomass within the reserve, and $X_{\mathrm{C}}$ is the mean biomass in the paired control site. A small constant was added to each value so that cases with observed mean biomass values of zero could be included in the analysis. Comparing response ratios allowed meaningful comparisons among species of widely different body sizes. Positive values of the LRR indicate greater biomass inside the marine reserve than outside. Negative values indicate the opposite. To calculate the mean and variance of the reserve effect for each species, we averaged the LRR across site pairings and used a linear model to include as a covariate our measure of habitat differences within pairs (i.e. the principal component scores of our habitat analysis). This procedure allowed us to account for fine-scale differences in habitat features and allowed us to robustly estimate each species' response to the marine reserve.

Reserve effect by species size. We examined community-wide evidence for trophic restructuring in 2 complementary ways. First, we determined whether the estimated response ratios varied systematically with species size. We assumed that species size served as a suitable proxy for trophic level due to the correlation of consumption of food types with gape and body size (Wainwright \& Richard 1995, Scharf et al. 2000), and its consequent determination of trophic relationships and ecological role on the level of fish communities (Jennings et al. 2001, but see Layman et al. 2005). Body size was summarized as the mean TL of individuals within a species observed in the study.

The relationship between LRR and species size was examined with a generalized additive model (GAM) using R statistical computing software version 2.6.2 (R Development Core Team 2007). Mean value of the LRR was modeled as a smooth function of species size, and generalized cross validation was used to determine the df for the optimal spline smoothing function. This approach provided a flexible way to find the best-fit description of general patterns in the relationship between species size and relative reserve effect. The overall pattern of the relationship was interpreted in 
light of our hypothesized general patterns (Fig. 1). In the analysis, the contribution of each species to the overall pattern was weighted by the strength of statistical evidence for the reserve effect (i.e. by the $Z$ scores for the difference in biomass between reserve and non-reserve sites). This procedure placed less emphasis on rare and/or highly variable species and more emphasis on species that exhibited a consistent difference in biomass between protected and unprotected sites. Consequently, any consistent patterns in the average response of species would be amplified. However, we believe that such a procedure is useful for characterizing the average responses of species within diverse communities. Like many ecological communities, the assemblage of reef fishes we studied was composed of few common species (whose responses to reserve protection may be well characterized) and many, rare species (whose responses may be described with less certainty). Weighting our analysis by a measure of precision associated with each species' response may therefore provide the best estimates of the overall, mean response of species (Hedges et al. 1999).

Reserve effect by trophic category. In a separate but similar analysis, we examined whether relative reserve effect varied among several trophic categories that combined trophic level (based on trophic score) with species size. Each species was assigned to 1 of 9 categories: (1) large piscivores (mainly consume other fishes, functionally act as 'large' predators); (2) large mixed carnivores (consume a combination of fishes and marine invertebrates, functionally act as 'large' predators); (3) large omnivores (consume a combination of algae, detritus, and marine animals, functionally act as 'large' consumers); (4) small piscivores (mainly consume other fish, functionally act as 'small' predators); (5) large herbivores (mainly consume algae, functionally act as 'large' herbivores); (6) small herbivores (mainly consume algae, functionally act as 'small' herbivores); (7) small mixed carnivores (consume a combination of fishes and marine invertebrates, functionally act as 'small' predators); (8) planktivores (mainly consume plankton from the water column); and (9) small omnivores (consume a combination of algae, detritus, and marine animals, functionally act as 'small' consumers) (see Appendix 1 for species' category assignments). Species assignments were based on field observations and trophic scores inferred from published gut content studies (Böhlke \& Randall 1963, Pitts 1991, Böhlke \& Chaplin 1993, Hixon \& Beets 1993, Michael 1993, Cervigón 1994, Sierra et al. 1994, Eggleston et al. 1998, Cortes 1999, Soares et al. 2003).

Mean values of relative reserve effect were compared among these 9 trophic categories. Although species were assigned to trophic categories based on the related attributes of trophic score and body size (among trophic categories mean body size and mean trophic score were correlated, $r=0.53$ ), these attributes may reflect slightly different aspects of an organism's ecological role and food web status. We therefore examined both size- and trophic-based patterns of community restructuring by comparing the response of trophic groups with respect to both the mean sizes and the mean trophic scores of fishes observed in each category. In this analysis, the contribution of each species to the mean values of relative reserve effect (response ratio) for each trophic category was again weighted by the strength of statistical evidence for the reserve effect. This comparison was designed to supplement the main analysis examining reserve effect as a function of body size.

Reserve effects on biomass distributions. In addition to analyzing the relative reserve effect for each trophic category, we also evaluated the proportional distribution of fish biomass among trophic categories inside and outside the marine reserve. The mean biomass per transect for each category was divided by the mean total biomass per transect. Proportional biomass within trophic categories was calculated for each site and averaged across sites to estimate mean values within the reserve and non-reserve treatments.

\section{RESULTS}

\section{Reserve effect by species size}

Analysis with the GAM indicated that the mean response ratio varied strongly with species' body size $(\mathrm{p}=$ $8.40 \times 10^{-4}$ ), and the generalized cross validation procedure indicated that the best-fit model for the mean effect was a spline with an estimated $6.79 \mathrm{df}$. This trendline exhibited a pattern consistent with a 3-level size-based trophic cascade (Fig. 2; see Fig. 1 for null models). Fig. 2 indicates that the largest fish species ( $>33 \mathrm{~cm}$ TL) were positively affected by the marine reserve. Many species of this size class were only observed within protected sites. In contrast, intermediatesized fishes (17 to $33 \mathrm{~cm}$ TL) were, on average, negatively affected by the marine reserve. Average reserve effect for smaller fishes ( 9 to $15 \mathrm{~cm}$ TL) was positive, though there was more variability in the response of these species. Finally, responses of the smallest fishes (<9 cm TL) were highly variable, with response values centered near zero. This overall pattern was robust to the number and size of species included in the analysis. Removing species with mean sizes $>33 \mathrm{~cm}$ TL and repeating the analysis still suggested that, on average, midsize fishes (17 to $33 \mathrm{~cm}$ TL) were negatively affected by the reserve $\left(p=4.33 \times 10^{-4}\right)$. Similarly, removing species $>16 \mathrm{~cm}$ TL still indicated that, on average, 


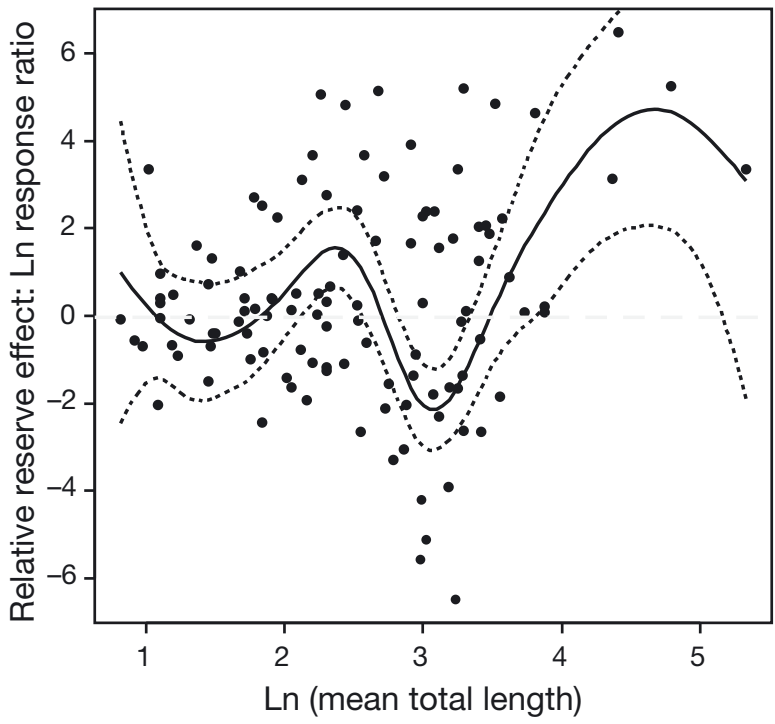

Fig. 2. Relative reserve effect as a function of species mean body size. Positive values of relative reserve effect indicate that biomass was greater within the reserve. Negative values indicate the opposite. $\bullet$ : mean value for a species ( $\mathrm{n}=113$ species). describes variation in relative reserve effect as a smooth function of species mean sizes. Dashed line at relative reserve effect $=0$ indicates no effect (neutral)

fishes with mean sizes of 9 to $15 \mathrm{~cm}$ TL increased in the reserve $(p=0.0149)$. Individual species' responses and effects of habitat differences within site pairings on response ratios are further detailed in Appendix 1.

\section{Reserve effect by trophic category}

Large piscivores as a group were the most positively affected trophic category of fishes, followed by small mixed carnivores and planktivores (Fig. 3). Small piscivores and large mixed carnivores exhibited negative mean LRR values, though only the response of small piscivores was statistically significant. Effects of the reserve on large and small omnivores and large and small herbivores were variable, but mean values tended to be positive. The overall pattern reflects the size-based differences in response ratios (Fig. 3a), and is consistent with a 3-level trophic cascade (Fig. 3b). When trophic categories were arranged in order of decreasing trophic score, a pattern of alternating responses to the reserve persists. Within the reserve sites large piscivores had greater biomass, small piscivores and large mixed carnivores had lower biomass, and categories of lower trophic level species such as small mixed carnivores and planktivores had greater biomass relative to unprotected sites. Notably, both small and large herbivores did not exhibit strong overall responses to the reserve, though mean values were positive.

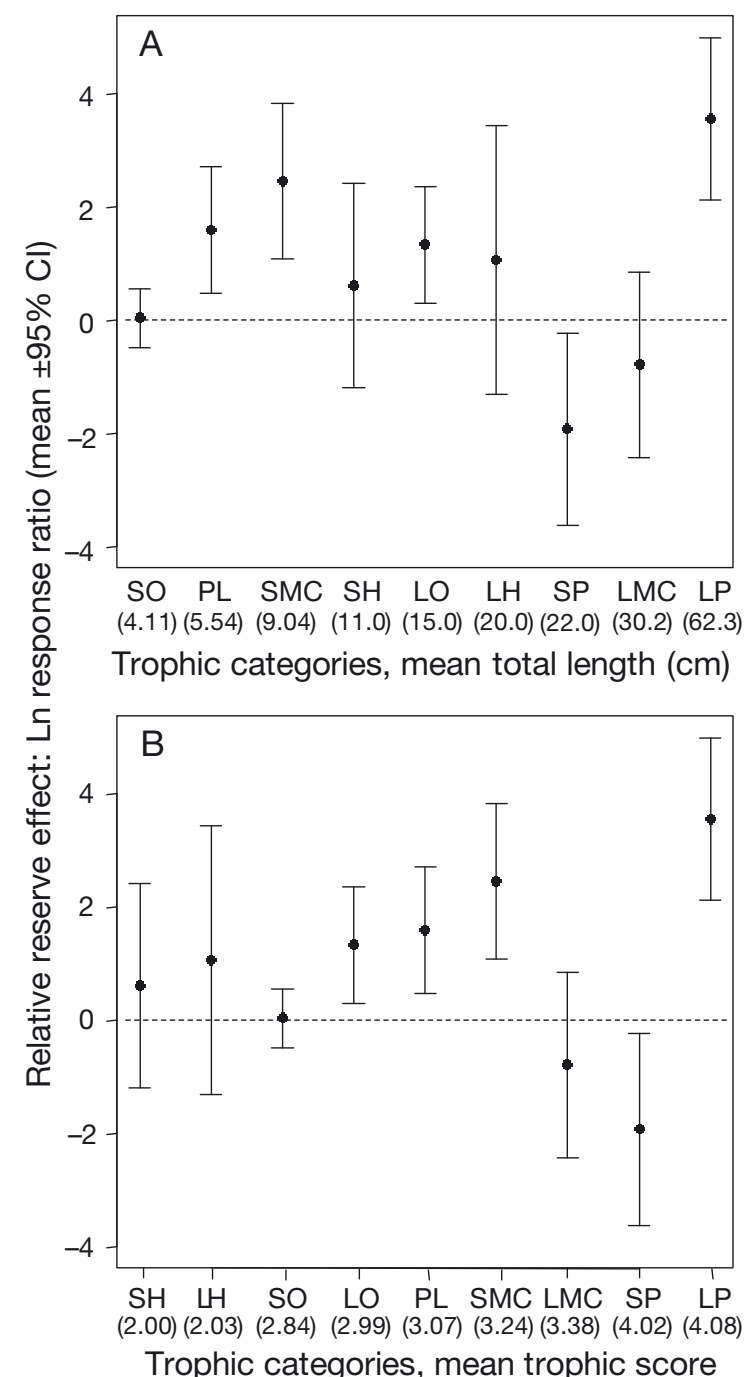

Fig. 3. Relative reserve effect by trophic category. (A) Trophic categories arranged left to right in order of increasing mean body size. (B) Trophic categories arranged left to right in order of increasing mean trophic score. Value is average reserve effect (ln [mean biomass inside marine reserve $+0.01 \div$ mean biomass outside marine reserve +0.01$]$ ) for all species in that trophic category, framed by $95 \%$ confidence intervals. LP: large piscivores $(\mathrm{n}=11$ species $)$; LMC: large mixed carnivores $(\mathrm{n}=20)$; SP: small piscivores $(\mathrm{n}=8)$; SMC: small mixed carnivores $(\mathrm{n}=18)$; LO: large omnivores $(\mathrm{n}=12)$; SO: small omnivores $(\mathrm{n}=10)$; PL: planktivores $(\mathrm{n}=10)$; LH: large herbivores $(n=4)$; $\mathrm{SH}$ : small herbivores $(\mathrm{n}=9)$

\section{Biomass distribution by trophic category}

The most notable differences in overall biomass between reserve and unprotected sites were that the reserve had a much higher biomass and a greater representation of high-trophic-level species. When trophic categories were pooled, the mean \pm SE biomass of fish inside the marine reserve was $487.5 \pm 334.0 \mathrm{~g}$ 
$\mathrm{m}^{-2}$, whereas mean biomass was $70.6 \pm 11.8 \mathrm{~g} \mathrm{~m}^{-2}$, outside the marine reserve. Inside the marine reserve, large piscivores accounted for $35.8 \pm 18.8 \%$ of the fish biomass, as opposed to $8.3 \pm 2.1 \%$ ) in unprotected sites (Fig. 4). All other categories comprised a similar or higher proportion of the fish biomass in unprotected sites, although many categories did increase in actual mean biomass within the reserve.

\section{DISCUSSION}

Although there was substantial variation among species with respect to the relative effect of the marine reserve on biomass, significant, overall changes were seen throughout the reef fish community. Our results suggested a restructuring of the fish community in response to marine reserve protection. On average, the largest species increased in biomass within the reserve, intermediate-sized species decreased, smaller species increased, and the smallest species exhibited variable responses. By pooling species into trophic categories, patterns of species' responses were consistent with a 3-level trophic cascade, and the overall results mirrored examples of simple trophic cascades with only a few interacting species (e.g. Estes \& Palmisano 1974). One interpretation of these patterns of species' responses to the reserve is that large predators such as sharks, barracuda, and large grouper inside the marine reserve likely reduced the biomass of smaller predatory fishes such as snapper and smaller grouper. Although we did not study trophic interactions directly, such interactions have been empirically demonstrated in the Bahamas (Eggleston et al. 1998, Stallings 2008). The lowered biomass of midsize predators in turn appeared to reduce the amount of predation on their prey, resulting in an increase in relative biomass

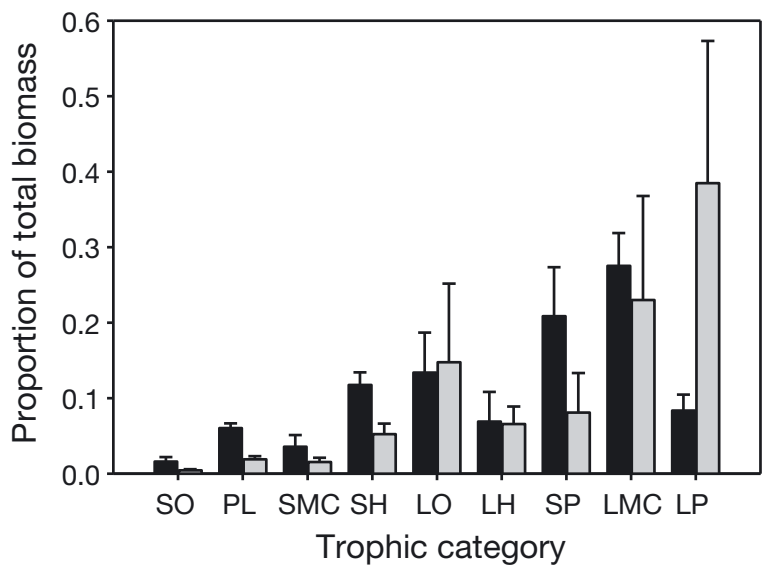

Fig. 4. Proportion of total biomass occupied by species in each trophic category in unprotected (black) and protected (grey) sites (mean $\pm 1 \mathrm{SE}$ ), and arranged left to right by increasing size. See Fig. 3 for definition of trophic categories in some of the smaller planktivorous and carnivorous species. Indeed, in the Bahamas, midsize predators including small grouper (Cephalophalus spp.) and hinds (Epinephelus spp.) have repeatedly been shown to be a significant source of predation on fishes in our planktivore and small mixed carnivore categories (Carr et al. 2002, Almany 2003, 2004, Stallings 2009b). The higher levels of variability in the reserve effect for smaller species may be due to a diffusion of the effects of the trophic cascade in the lower levels of the food web. This pattern would be expected because of the wider species/biomass base and more varied ecological interactions that exist at lower trophic levels (Cohen et al. 2003). As greater numbers of species interact on multiple ecological levels, removal or reintroduction of even strongly interacting species can have muted effects due to the compensation afforded by multiple prey species (Strong 1992). Despite these moderating effects, widespread changes in the structure of the reef fish community could be observed in our data.

Restructuring of fish communities has been revealed by the reintroduction of top predatory species in a variety of marine systems (Pace et al. 1999, Pinnegar et al. 2000). Here we observed evidence for community restructuring based on both body size and trophic score. To some extent this likely reflects the correlation between these 2 attributes (mean body size and mean trophic level were well correlated for our trophic categories: $r=0.53$ ). However, these 2 variables are also worth examining separately, as some differences occur when comparing general reserve responses by mean trophic score and by mean size (see differences in Fig. 3). Although using trophic categories to pool species for analyses of reserve effect is a useful tool for observing and interpreting changes on the scale of whole food webs, this method also has drawbacks. Trophic categories and levels may vary from study to study, are somewhat arbitrary, and are often incomplete in describing ecological relationships among species. Trophic score is calculated based on samples of diet and/or isotope analyses and an assessment of the average number of steps up a linear food chain for items found in a species' diet (e.g. Muñoz \& Ojeda 1997, Friedlander \& DeMartini 2002). Although this approach is informative, for assemblages such as coralreef fishes, body size is a different and perhaps better predictor of important consumptive relationships. For example, in a typical trophic level assignment, large fishes with mixed diets may consume small, carnivorous fishes despite having a lower estimated trophic level. For these reasons, we began our analyses with a size-based approach using species mean TL as a predictor of reserve effect.

It is also likely that within this diverse assemblage of reef fishes, many types of interactions play an impor- 
tant role in determining community structure. For example, in addition to direct consumption, large predatory species can also have non-lethal, negative effects on the biomass of smaller fishes. In the Bahamas, large groupers may out-compete smaller groupers for food and/or territory, causing a reduction in growth rates of small groupers (Stallings 2008). Growth rates can also be reduced when prey species choose inferior habitats in a tradeoff with predator avoidance (Werner et al. 1983). Such effects could contribute to the observed reduction in biomass of midsize and mid-trophic level species such as small piscivores and large mixed carnivores.

Within this study, the responses of midsize species may have been especially variable, since one might expect these species to experience a mix of positive and negative reserve effects. While midsize species were likely to be at greater risk of predation due to the increased abundance of large piscivores within the marine reserve, they may have also experienced some alleviation from fishing pressure. Although large piscivores have been most affected by fishing, many midsize species are fished in unprotected Bahamian coral reef habitats (CRFM 2005, authors' pers. obs.). For example, large parrotfishes in the ECLSP have greater abundances within the reserve due to protection from fish traps even though abundances and sizes of large piscivores are also greater (Mumby et al. 2006). This is due to the escape of large-bodied herbivores from predation due to the limitation of consumption by predator gape size.

Mumby et al. (2006) also showed that large herbivore species responded to reserve protection with increased densities but no change in mean size relative to unprotected sites, whereas smaller species had lower mean sizes inside the reserve compared to outside, but showed no change in relative densities. Similar, size-based differences in response to protection within trophic categories were also observed in our study: larger classes of piscivores, omnivores, and herbivores showed more positive responses to the reserve compared to smaller classes of these same categories. These within-category differences may be due to the higher risk of predation upon smaller individuals within the reserve, and a higher risk of capture in fisheries for larger individuals outside of the reserve.

Within the assemblage of fishes observed in this study, herbivores are an exception to the general, direct relationship between body size and trophic level, because some herbivores (particularly parrotfishes) can be quite large as adults. Consequently, the pattern of size-based responses to reserve protection observed in Fig. 2 does not suggest a simple trophic cascade involving top carnivores, secondary carnivores, and herbivores. Rather, the alternating patterns of abundance were observed among other trophic categories, for example, large piscivores, small piscivores, and planktivores. Even though, on average, herbivores did not exhibit a strong response to reserve protection, our results nonetheless suggest that the community of fishes is structured, at least in part, by strong, topdown processes. Such effects may be detected even without strong responses from herbivores and primary producers because of direct (Carpenter et al. 1985) and indirect (Stallings 2008) interactions among largebodied and small-bodied carnivores/omnivores.

Based on our assignment of species to individual trophic levels, it is apparent that major shifts in the distribution of biomass throughout the food web had occurred between unprotected and protected areas. The large disparity in proportional biomass between reserve and non-reserve sites in the large piscivore category was a major finding of this analysis, given that most other categories also had higher mean biomasses inside the marine reserve. Even so, our results support conclusions from studies of the northwest Hawaiian Islands (Friedlander \& DeMartini 2002) and the Line Islands (Stevenson et al. 2007, Sandin et al. 2008) suggesting that relatively healthy, unfished reefs such as those found within the ECLSP may normally have as much as $50 \%$ of the fish biomass concentrated in top-level predatory species. The major reduction in average biomass for small piscivores and large mixed carnivores within the reserve, combined with associated increases in small mixed carnivores and planktivores suggests that reintroduction of these large piscivores can alter the distribution of species in other functional groups. Protection of overfished predators has been linked to the restoration of functional groups such as herbivores and detritivores in past studies (Kramer \& Heck Jr. 2007), which can lead to increased coral reef health. These effects can have strong implications for the management of fisheries and marine reserves (Bohnsack 1998, Lirman 2001, see Roberts 1995 for review). Similar to results reported by Newman et al. (2006), our results indicated that the average biomass of all fishes combined was approximately $7 \times$ greater inside the marine reserve than outside, indicating much greater total standing fish stock in protected fish communities.

The salient pattern from our study is one of significant alteration of the distribution of biomass at the top, intermediate, and small sizes of species in the reef fish food web inside the marine reserve vs. outside. This type of community-wide restructuring of a complex marine food web has rarely been described (but see Guidetti \& Sala 2007). Fishing in virtually all areas of the world continues to deplete populations of largebodied predatory species, with there being only small islands of refuge in the form of marine reserves or 
areas inaccessible to fishing. Given the results of this and similar studies, it should not be assumed that fishing only affects targeted species. The indirect effects that propagate throughout the food web can cause substantial shifts in biomass distributions among species, size groups, and trophic levels. These indirect effects should be taken into account to improve the effectiveness of management and conservation efforts.

Acknowledgements. This undergraduate research project was made possible through grants to R.W.L. from Oregon State University and the Howard Hughes Medical Institute, and by OCE-05-50709 and 08-51162 from the National Science Foundation to M. A. Hixon. Field support was provided by B. Gadd and the Perry Institute for Marine Science, and field assistance was provided by J. Moye and B. Gadd. This paper is a chapter from R.W.L.'s undergraduate honors thesis, which benefited from valuable comments by committee members M. A. Hixon and B. A. Menge, and 5 anonymous reviewers.

\section{LITERATURE CITED}

Almany GR (2003) Priority effects in coral reef fish communities. Ecology 84:1920-1935

Almany GR (2004) Differential effects of habitat complexity, predators and competitors on abundance of juvenile and adult coral reef fishes. Oecologia 141:105-113

Böhlke JE, Chaplin CCG (1993) Fishes of the Bahamas and adjacent tropical waters, 2nd edn. University of Texas Press, Austin, TX

Böhlke JE, Randall JE (1963) The fishes of the western Atlantic serranid genus Gramma. Proc Acad Nat Sci Philadelphia 115:33-52

Bohnsack JA (1998) Application of marine reserves to reef fisheries management. Aust J Ecol 9:1216-1227

Bohnsack JA, Harper DE (1988) Length-weight relationships of selected marine reef fishes from the southeastern United States and the Caribbean. NOAA Technical Memorandum NMFS-SEFC-215

Carpenter SR, Kitchell JF (1988) Consumer control of lake productivity. Bioscience 38:764-769

> Carpenter SR, Kitchell JF, Hodgson JR (1985) Cascading trophic interactions and lake productivity. Bioscience 35: 634-639

Carr MH, Anderson TW, Hixon MA (2002) Biodiversity, population regulation, and the stability of coral-reef fish communities. Proc Natl Acad Sci USA 99:11241-11245

Cervigón F (1994) Los peces marinos de Venezuela, Vol 3. Fundación Científica Los Roques, Caracas

Chapman MR, Kramer DL (1999) Gradients in coral reef fish density and size across the Barbados Marine Reserve boundary: effects of reserve protection and habitat characteristics. Mar Ecol Prog Ser 181:81-96

Cohen JE, Jonsson T, Carpenter SR (2003) Ecological community description using the food web, species abundance, and body size. Proc Natl Acad Sci USA 100:1781-1786

> Coleman FC, Williams SL (2002) Overexploiting marine ecosystem engineers: potential consequences for biodiversity. Trends Ecol Evol 17:40-44

> Cortes E (1999) Standardized diet compositions and trophic levels of sharks. ICES J Mar Sci 56:707-717

> Côté IM, Mosqueira I, Reynolds JD (2001) Effects of marine reserve characteristics on the protection of fish popula- tions: a meta-analysis. J Fish Biol 59:178-189

CRFM (Caribbean Regional Fisheries Mechanism) (2005) Report of the first annual Caribbean Regional Fisheries Mechanism scientific meeting. CRFM Fishery Report, Vol 11

Daskalov GM (2002) Overfishing drives a trophic cascade in the Black Sea. Mar Ecol Prog Ser 225:53-63

Dayton PK, Sala E, Tegner MJ, Thrush S (2000) Marine reserves: parks, baselines, and fishery enhancement. Bull Mar Sci 66:617-634

Eggleston DB, Grover JJ, Lipcius RN (1998) Ontogenetic diet shifts in Nassau grouper: trophic linkages and predatory impact. Bull Mar Sci 63:111-126

- Estes JA, Palmisano JF (1974) Sea otters: their role in structuring nearshore communities. Science 185:1058-1060

Frank KT, Petrie B, Choi JS, Leggett WC (2005) Trophic cascades in a formerly cod-dominated ecosystem. Science 308:1621-1623

Friedlander AM, DeMartini EE (2002) Contrasts in density, size, and biomass of reef fishes between the northwestern and the main Hawaiian islands: the effects of fishing down apex predators. Mar Ecol Prog Ser 230:253-264

> Gordon HS (1991) The economic theory of a common-property resource: the fishery. Bull Math Biol 53:231-252

> Graham NAJ, Evans RD, Russ GR (2003) The effects of marine reserve protection on the trophic relationships of reef fishes on the Great Barrier Reef. Environ Conserv 30: 200-208

> Guidetti P, Sala E (2007) Community-wide effects of marine reserves in the Mediterranean Sea. Mar Ecol Prog Ser 335: $43-56$

> Halpern B (2003) The impact of marine reserves: Do reserves work and does reserve size matter? Ecol Appl 13:117-137

Hedges LV, Gurevitch J, Curtis PS (1999) The meta-analysis of response ratios in experimental ecology. Ecology 80: 1150-1156

- Hixon MA, Beets JP (1993) Predation, prey refuges, and the structure of coral-reef fish assemblages. Ecol Monogr 63: $77-101$

Jackson JBC, Kirby MX, Berber WH, Bjorndal KA and others (2001) Historical overfishing and the recent collapse of coastal ecosystems. Science 293:629-637

> Jennings S, Polunin NVC (1997) Impacts of predator depletion by fishing on the biomass and diversity of non-target reef fish communities. Coral Reefs 16:71-82

Jennings S, Pinnegar JK, Polunin NVC, Boon TW (2001) Weak cross-species relationships between body size and trophic level belie powerful size-based trophic structuring in fish. J Anim Ecol 70:934-944

Kramer KL, Heck KL Jr. (2007) Top-down trophic shifts in Florida Keys patch reef marine protected areas. Mar Ecol Prog Ser 349:111-123

Layman CA, Winemiller KO, Arrington DA, Jepsen DB (2005) Body size and trophic position in a diverse tropical food web. Ecology 86:2530-2535

Lipcius RN, Stockhausen WT, Eggleston DB (2001) Marine reserve for Caribbean spiny lobster: empirical evaluation and theoretical metapopulation recruitment dynamics. Mar Freshw Res 52:1589-1598

> Lirman D (2001) Competition between macroalgae and corals: effects of herbivore exclusion and increased algal biomass on coral survivorship and growth. Coral Reefs 19: 392-399

> Luckhurst BE, Luckhurst K (1978) Analysis of the influence of substrate variables on coral reef fish communities. Mar Biol 49:317-323

McClanahan TR, Mangi SC (2004) Gear-based management 
of a tropical artisanal fishery based on species selectivity and capture size. Fish Manag Ecol 11:51-60

McClanahan TR, Nyawira AM (1988) Changes in Kenyan coral reef community structure and function due to exploitation. Hydrobiologia 166:269-276

Michael SW (1993) Reef sharks and rays of the world. A guide to their identification, behavior, and ecology. Sea Challengers, Monterey, CA

Mumby PJ, Dahlgren CP, Harborne AR, Kappel CV and others (2006) Fishing, trophic cascades, and the process of grazing on coral reefs. Science 311:98-101

Mumby PJ, Harborne AR, Williams J, Kappel CV and others (2007) Trophic cascade facilitates coral recruitment in a marine reserve. Proc Natl Acad Sci USA 104:8362-8367

Muñoz AA, Ojeda FP (1997) Feeding guild structure of a rocky intertidal fish assemblage in central Chile. Environ Biol Fishes 49:471-479

Newman MJH, Paredes GA, Sala E, Jackson JBC (2006) Structures of Caribbean coral reef communities across a large gradient of fish biomass. Ecol Lett 9:1216-1227

Öhman MC, Rajasuriya A (1998) Relationships between habitat structure and fish communities on coral. Environ Biol Fishes 53:19-31

Pace ML, Cole JJ, Carpenter SS, Kitchell JF (1999) Trophic cascades revealed in diverse ecosystems. Trends Ecol Evol $14: 483-488$

Paine RT (1980) Food webs: linkages, interaction strength, and community infrastructure. J Anim Ecol 49:667-685

Parrish JD (1987) The trophic biology of snappers and groupers. In: Polovina JJ, Ralston S (eds) Tropical snappers and groupers: biology and fisheries management. Westview Press, Boulder, CO, p 405-463

Pauly D (1995) Anecdotes and the shifting baseline syndrome of fisheries. Trends Ecol Evol 10:430

Pauly D, Chirstensen V, Dalsgaard J, Froese R, Torres F (1998) Fishing down marine food webs. Science 279: 860-863

Pinnegar JK, Polunin NVC, Francour P, Badalamente F, Chemello R and others (2000) Trophic cascades in benthic marine ecosystems: lessons for fisheries and protected area management. Environ Conserv 27:179-200

Pitts PA (1991) Comparative use of food and space by three Bahamian butterflyfishes. Bull Mar Sci 48:749-756

> Polunin NVC, Roberts CM (1993) Greater biomass and value of target coral-reef fishes in two small Caribbean marine reserves. Mar Ecol Prog Ser 100:167-176

Power ME (1990) Effects of fish in river food webs. Science 250:811-814

R Development Core Team (2007) R: a language and environment for statistical computing. R Foundation for Statistical Computing, Vienna

Roberts CM (1995) Effects of fishing on the ecosystem structure of coral reefs. Conserv Biol 9:988-995

Russ GR, Alcala AC (1996) Do marine reserves export adult fish biomass? Evidence from Apo Island, central Philippines. Mar Ecol Prog Ser 132:1-9

Sandin SA, Smith JE, DeMartini EE, Dinsdale EA, Donner SD and others (2008) Baselines and degradation of coral reefs in the northern Line Islands. PLos One 3:e1548, doi: 10.1371/journal.pone.0001548

Scharf FS, Juanes F, Rountree RA (2000) Predator size-prey size relationships of marine fish predators: interspecific variation and effects of ontogeny and body size on trophicniche breadth. Mar Ecol Prog Ser 208:229-248

> Sheppard C (1995) The shifting baseline syndrome. Mar Pollut Bull 30:766-767

Sierra LM, Claro R, Popova OA (1994) Alimentacion y relaciones tróficas. In: Rodolfo Claro (ed) Ecología de los Peces Marinos de Cuba. Instituto de Oceanología Academia de Ciencias de Cuba and Centro de Investigaciones de Quintana Roo, Chetumal, p 263-284

Sluka R, Chiappone M, Sullivan KM, Wright R (1997) The benefits of a marine fishery reserve for Nassau Grouper Epinephelus striatus in the central Bahamas. Proc 8th Coral Reef Sym 2:1961-1964

Soares MSC, Sousa L, Barreiros JP (2003) Feeding habits of the lizardfish Synodus saurus (Linnaeus, 1758) (Actinopterygii: Synodontidae) from the Azores. J Ichthyol Aquat Biol 7:29-38

Stallings CD (2008) Indirect effects of an exploited predator on recruitment of coral-reef fishes. Ecology 89:2090-2095

Stallings CD (2009a) Fishery-independent data reveal negative effect of human population density on Caribbean predatory fish communities. PLos One 4:e5333, doi: 10.1371/journal.pone.0005333

Stallings CD (2009b) Predator identity and recruitment of coral-reef fishes: indirect effects of fishing. Mar Ecol Prog Ser 383:251-259

Steneck RS (1998) Human influences on coastal ecosystems: does overfishing create trophic cascades? Trends Ecol Evol 13:429-430

Stevenson C, Katz LS, Micheli F, Block B and others (2007) High apex predator biomass on remote Pacific islands. Coral Reefs 26:47-51

> Stoner AW, Ray-Culp M (2000) Evidence for Allee effects in an over-harvested marine gastropod: density-dependent mating and egg production. Mar Ecol Prog Ser 202: 297-302

> Strauss SY (1991) Indirect effects in community ecology: their definition, study, and importance. Trends Ecol Evol 6: 206-210

Strong DR (1992) Are trophic cascades all wet? Differentiation and donor-control in speciose ecosystems. Ecology 73: 747-754

Wainwright PC, Richard BA (1995) Predicting patterns of prey use from morphology of fishes. Environ Biol Fishes 44: 97-113

Wantiez L, Thollot P, Kulbicki M (1997) Effects of marine reserves on coral reef fish communities from five islands in New Caledonia. Coral Reefs 16:215-224

Werner EE, Gilliam JF (1984) The ontogenetic niche and species interactions in size-structured populations. Annu Rev Ecol Syst 15:393-425

Werner EE, Gilliam JF, Hall DJ, Mittelbach GG (1983) An experimental test of the effects of predation risk on habitat use in fish. Ecology 64:1540-1548 
Appendix 1. Summary data for observed reef fish species

\begin{tabular}{|c|c|c|c|c|c|c|c|c|c|}
\hline \multirow[t]{2}{*}{ Species } & \multirow[t]{2}{*}{ Common name } & \multirow[t]{2}{*}{ Trophic category } & \multicolumn{2}{|c|}{$\begin{array}{l}\text { Relative reserve } \\
\text { effect log } \\
\text { response ratio }\end{array}$} & \multicolumn{2}{|c|}{$\begin{array}{l}\text { Within pair } \\
\text { habitat effects }\end{array}$} & \multirow[t]{2}{*}{$\begin{array}{c}\mathrm{TL} \\
(\mathrm{cm})\end{array}$} & \multirow[t]{2}{*}{ SD } & \multirow[t]{2}{*}{$\begin{array}{c}\text { No. } \\
\text { observed }\end{array}$} \\
\hline & & & Mean & $\mathrm{SE}$ & Coef. & $\mathrm{SE}$ & & & \\
\hline Abedufduf saxatilis & Sergeant major & Planktivore & -0.63 & 2.32 & 3.20 & 1.77 & 13.33 & 2.73 & 57 \\
\hline Acanthemblemaria maria & Secretary blenny & Small omnivore & 0.29 & 0.33 & 0.10 & 0.25 & 3.00 & 0.00 & 1 \\
\hline Acanthurus bahianus & Ocean surgeonfish & Small herbivore & -3.30 & 2.17 & -0.29 & 1.66 & 16.16 & 3.59 & 43 \\
\hline Acanthurus chirurgus & Doctorfish & Small herbivore & 3.20 & 1.14 & -1.23 & 0.87 & 15.19 & 3.92 & 53 \\
\hline Acanthurus coereulus & Blue tang & Small herbivore & -0.10 & 0.46 & -0.30 & 0.35 & 12.53 & 5.45 & 123 \\
\hline Anisotremus virginicus & Porkfish & Large mixed carnivore & 0.12 & 2.65 & -2.36 & 2.02 & 27.50 & 3.54 & 2 \\
\hline Apogon binotatus & Barred cardinalfish & Small omnivore & -0.08 & 0.60 & 0.49 & 0.46 & 2.25 & 0.50 & 4 \\
\hline Aulostomus maculatus & Trumpetfish & Small piscivore & -1.36 & 2.57 & 1.85 & 1.96 & 26.60 & 8.00 & 25 \\
\hline Balistes vetula & Queen triggerfish & Large mixed carnivore & 3.34 & 2.27 & 0.46 & 1.73 & 25.83 & 7.36 & 6 \\
\hline Bodianus rufus & Spanish hogfish & Small mixed carnivore & -0.84 & 2.79 & 2.29 & 2.13 & 6.36 & 7.63 & 25 \\
\hline Calamus calamus & Saucereye porgy & Large mixed carnivore & -2.65 & 1.35 & 4.16 & 1.03 & 30.57 & 5.93 & 44 \\
\hline Canthigaster rostrata & Sharpnose puffer & Small omnivore & 0.41 & 0.77 & 0.86 & 0.58 & 5.55 & 2.78 & 122 \\
\hline Caranx latus & Horse-eye jack & Large piscivore & 4.85 & 3.01 & -2.30 & 2.30 & 33.71 & 12.28 & 85 \\
\hline Caranx ruber & Bar jack & Small piscivore & -0.87 & 3.71 & 2.18 & 2.83 & 19.11 & 4.82 & 129 \\
\hline Carcharinus perezii & Reef shark & Large piscivore & 3.35 & 2.93 & -3.32 & 2.24 & 207.50 & 65.00 & 4 \\
\hline Cephalopholis cruentatus & Graysby & Small piscivore & 3.91 & 2.36 & 1.08 & 1.80 & 18.35 & 5.31 & 51 \\
\hline Cephalopholis fulvus & Coney & Small piscivore & -5.58 & 2.64 & -0.45 & 2.02 & 19.69 & 6.70 & 16 \\
\hline Chaetodipterus faber & Atlantic spadefish & Large mixed carnivore & 1.78 & 2.01 & 0.60 & 1.53 & 25.00 & 0.00 & 1 \\
\hline Chaetodon capistratus & Foureye butterflyfish & Large omnivore & -1.10 & 2.12 & 1.13 & 1.62 & 11.34 & 2.51 & 41 \\
\hline Chaetodon ocellatus & Spotfin butterflyfish & Large omnivore & 3.67 & 2.58 & 0.92 & 1.97 & 13.11 & 3.60 & 37 \\
\hline Chaetodon sedentatus & Reef butterflyfish & Large omnivore & 0.33 & 0.34 & -0.23 & 0.26 & 10.00 & 0.00 & 2 \\
\hline Cheatodon aculeatus & Longnose butterflyfish & Large omnivore & 3.11 & 1.45 & 0.96 & 1.11 & 8.37 & 2.73 & 35 \\
\hline Cheatodon striatus & Banded butterflyfish & Large omnivore & -1.25 & 0.95 & -1.43 & 0.73 & 10.00 & 0.00 & 1 \\
\hline Chromis cyanea & Blue chromis & Planktivore & 0.36 & 0.13 & 0.16 & 0.10 & 6.77 & 3.58 & 1449 \\
\hline Chromis insolata & Sunshinefish & Planktivore & 0.97 & 0.85 & -0.97 & 0.65 & 3.00 & 0.85 & 12 \\
\hline Chromis multilineata & Brown chromis & Planktivore & 2.70 & 1.46 & 1.67 & 1.12 & 5.92 & 5.47 & 39 \\
\hline Clepticus parrae & Creole wrasse & Planktivore & -0.15 & 3.26 & 1.13 & 2.49 & 5.32 & 3.56 & 1218 \\
\hline Coryphopterus dicrus & Colon goby & Small omnivore & -0.08 & 1.43 & 0.69 & 1.09 & 3.72 & 1.00 & 72 \\
\hline $\begin{array}{l}\text { Coryphopterus } \\
\text { glaucofraenum }\end{array}$ & Bridled goby & Small omnivore & 1.61 & 1.11 & 2.11 & 0.85 & 3.92 & 1.86 & 495 \\
\hline Coryphopterus personatus & Masked goby & Planktivore & 3.34 & 0.85 & 1.48 & 0.65 & 2.77 & 1.26 & 6792 \\
\hline Dasyatis centroura & Roughtail stingray & Large mixed carnivore & 5.25 & 2.45 & 3.73 & 1.87 & 120.00 & 0.00 & 2 \\
\hline Diodon holocanthus & Balloonfish & Large mixed carnivore & -3.06 & 0.93 & 2.58 & 0.71 & 17.50 & 3.54 & 2 \\
\hline Diodon hystrix & Porcupinefish & Large mixed carnivore & 0.08 & 0.09 & 0.02 & 0.07 & 48.33 & 2.89 & 3 \\
\hline Elacatinus horsti & Yellowline goby & Small omnivore & -0.05 & 0.48 & 0.38 & 0.37 & 3.00 & 0.00 & 2 \\
\hline Epinephelus guttatus & Red hind & Small piscivore & -5.11 & 2.22 & 0.58 & 1.69 & 20.56 & 6.35 & 9 \\
\hline Epinephelus striatus & Nassau grouper & Large piscivore & 0.88 & 2.87 & 3.79 & 2.19 & 37.50 & 11.54 & 18 \\
\hline Ginglymostoma cirratum & Nurse shark & Large piscivore & 4.64 & 2.86 & -2.47 & 2.18 & 45.00 & 0.00 & 2 \\
\hline Gnatholepis thompsoni & Goldspot goby & Small omnivore & -0.70 & 0.46 & -0.10 & 0.35 & 4.32 & 2.06 & 107 \\
\hline Gobiosoma evelynae & Sharknose goby & Small omnivore & 0.47 & 0.83 & 0.03 & 0.63 & 3.31 & 0.70 & 16 \\
\hline Gobiosoma genie & Cleaning goby & Small omnivore & -0.67 & 0.42 & -0.03 & 0.32 & 3.27 & 0.63 & 100 \\
\hline Gramma loreto & Fairy basslet & Small omnivore & -0.40 & 0.91 & 0.22 & 0.69 & 4.48 & 2.42 & 1532 \\
\hline Gramma melacra & Blackcap basslet & Small omnivore & 1.32 & 1.16 & -1.31 & 0.89 & 4.37 & 1.61 & 19 \\
\hline Gymnothorax moringa & Spotted moray eel & Large piscivore & 1.27 & 1.46 & 0.25 & 1.11 & 30.00 & 0.00 & 1 \\
\hline Haemulon album & White margate & Small piscivore & -0.54 & 4.07 & 3.88 & 3.11 & 30.29 & 3.29 & 17 \\
\hline Haemulon flavolineatum & French grunt & Large mixed carnivore & -2.03 & 1.88 & 1.99 & 1.44 & 17.84 & 4.13 & 610 \\
\hline Haemulon melanurum & Cottonwick & Small mixed carnivore & -2.03 & 1.30 & 0.93 & 0.99 & 2.97 & 0.90 & 32 \\
\hline Haemulon plumierii & White grunt & Large mixed carnivore & -1.65 & 2.19 & 1.75 & 1.67 & 24.26 & 3.79 & 95 \\
\hline Haemulon sciurus & Bluestriped grunt & Large mixed carnivore & -6.49 & 2.40 & 3.35 & 1.83 & 25.47 & 3.15 & 85 \\
\hline Halichoeres bivittatus & Slippery dick & Small mixed carnivore & 0.51 & 0.95 & 0.32 & 0.73 & 8.04 & 4.45 & 122 \\
\hline Halichoeres garnoti & Yellowhead wrasse & Small mixed carnivore & -0.40 & 0.38 & 0.47 & 0.29 & 5.63 & 4.09 & 1226 \\
\hline Halichoeres maculipinna & Clown wrasse & Small mixed carnivore & -1.94 & 1.19 & -1.07 & 0.91 & 8.68 & 3.34 & 56 \\
\hline Halichoeres pictus & Rainbow wrasse & Planktivore & -0.90 & 0.67 & -0.11 & 0.51 & 3.41 & 2.06 & 984 \\
\hline Halichoeres radiatus & Puddingwife & Small mixed carnivore & 0.50 & 3.18 & -0.65 & 2.43 & 9.44 & 6.69 & 9 \\
\hline Hemiemblemaria simulus & Wrasse blenny & Small omnivore & -1.50 & 0.66 & -0.44 & 0.50 & 4.25 & 0.50 & 4 \\
\hline Hemiramphus brasiliensis & Ballyhoo & Large omnivore & -2.12 & 2.43 & -0.42 & 1.86 & 15.29 & 3.63 & 35 \\
\hline Heteropriacanthus cruent. & Glasseye snapper & Large mixed carnivore & -1.78 & 1.56 & 1.77 & 1.19 & 21.67 & 2.89 & 3 \\
\hline Holocanthus ciliaris & Queen angelfish & Large omnivore & 2.37 & 2.54 & 4.27 & 1.94 & 20.52 & 7.33 & 27 \\
\hline
\end{tabular}


Appendix 1 (continued)

\begin{tabular}{|c|c|c|c|c|c|c|c|c|c|}
\hline \multirow[t]{2}{*}{ Species } & \multirow[t]{2}{*}{ Common name } & \multirow[t]{2}{*}{ Trophic category } & \multicolumn{2}{|c|}{$\begin{array}{l}\text { Relative reserve } \\
\text { effect log } \\
\text { response ratio }\end{array}$} & \multicolumn{2}{|c|}{$\begin{array}{l}\text { Within pair } \\
\text { habitat effects }\end{array}$} & \multirow[t]{2}{*}{$\begin{array}{l}\mathrm{TL} \\
(\mathrm{cm})\end{array}$} & \multirow[t]{2}{*}{$\begin{array}{l}\mathrm{SD} \\
\mathrm{o}\end{array}$} & \multirow[t]{2}{*}{$\begin{array}{c}\text { No. } \\
\text { observed }\end{array}$} \\
\hline & & & Mean & $\mathrm{SE}$ & Coef. & $\mathrm{SE}$ & & & \\
\hline Holocanthus tricolor & Rock beauty & Large omnivore & 1.72 & 2.26 & 0.71 & 1.73 & 14.30 & 5.97 & 23 \\
\hline Holocentrus adscensionis & Squirrelfish & Large mixed carnivore & 2.40 & 1.92 & -1.16 & 1.47 & 21.70 & 4.70 & 132 \\
\hline Holocentrus rufus & Longspine squirrelfish & Large mixed carnivore & -4.21 & 2.17 & -0.84 & 1.66 & 19.84 & 4.55 & 184 \\
\hline Hypoplectrus puella & Barred hamlet & Small mixed carnivore & 4.83 & 1.04 & 2.30 & 0.79 & 11.43 & 2.54 & 42 \\
\hline Hypoplectrus spp. & Tan hamlet & Small mixed carnivore & 0.25 & 0.22 & -0.24 & 0.16 & 12.50 & 3.54 & 2 \\
\hline Hypoplectrus unicolor & Buttered hamlet & Small mixed carnivore & 2.41 & 1.72 & -0.09 & 1.31 & 12.50 & 3.54 & 2 \\
\hline Kyphosid sp. & Bermuda/yellow chub & Large omnivore & 0.23 & 2.03 & -4.57 & 1.55 & 48.17 & 17.24 & 30 \\
\hline Lactophrys trigonus & Trunkfish & Large omnivore & -1.86 & 2.09 & -0.62 & 1.60 & 35.00 & 0.00 & 1 \\
\hline Liopropoma rubrae & Peppermint basslet & Small omnivore & 2.26 & 1.80 & -1.46 & 1.38 & 7.00 & 2.74 & 5 \\
\hline Lucayablennius zingaro & Arrow blenny & Small omnivore & 0.74 & 0.64 & -0.73 & 0.49 & 4.25 & 0.50 & 4 \\
\hline Lutjanus apodus & Schoolmaster & Small piscivore & -1.66 & 2.46 & 1.74 & 1.87 & 25.73 & 6.80 & 152 \\
\hline Lutjanus griseus & Gray snapper & Small piscivore & -2.63 & 3.40 & 2.87 & 2.59 & 26.92 & 3.50 & 65 \\
\hline Lutjanus mahogoni & Mahogany snapper & Small piscivore & -2.32 & 0.91 & 5.46 & 0.70 & 22.48 & 5.28 & 117 \\
\hline Lutjanus synagris & Lane snapper & Small piscivore & -0.12 & 2.69 & 4.05 & 2.05 & 26.56 & 7.47 & 16 \\
\hline Malacanthus plumieri & Sand tilefish & Large mixed carnivore & 1.65 & 1.70 & -1.13 & 1.30 & 18.33 & 10.41 & 3 \\
\hline Malacoctenus boehlkei & Diamond blenny & Small omnivore & -2.45 & 2.37 & 0.27 & 1.81 & 6.29 & 2.54 & 51 \\
\hline Malacoctenus gilli & Dusky blenny & Small omnivore & 0.40 & 0.41 & -0.27 & 0.32 & 3.00 & 0.00 & 1 \\
\hline Malacoctenus macropus & Rosy blenny & Small omnivore & 1.01 & 1.37 & 0.33 & 1.04 & 5.33 & 2.42 & 6 \\
\hline Malacoctenus triangulatus & Saddled blenny & Small omnivore & -0.39 & 1.52 & -1.68 & 1.16 & 4.39 & 0.57 & 49 \\
\hline Microspathodon chrysurus & Yellowtail damselfish & Large omnivore & -2.66 & 1.84 & 0.54 & 1.40 & 12.79 & 4.62 & 29 \\
\hline Monacanthus tuckeri & Slender filefish & Large omnivore & 2.77 & 1.93 & -0.43 & 1.47 & 10.00 & 0.00 & 6 \\
\hline Mulloidichthys martinicus & Yellow goatfish & Large mixed carnivore & -3.90 & 2.55 & 0.83 & 1.95 & 24.06 & 5.75 & 85 \\
\hline Mycteroperca bonaci & Black grouper & Large piscivore & 6.50 & 3.27 & -0.27 & 2.50 & 82.00 & 41.47 & 5 \\
\hline Mycteroperca interstitialis & Yellowmouth grouper & Large piscivore & 2.06 & 1.81 & -2.05 & 1.38 & 31.67 & 2.89 & 3 \\
\hline Mycteroperca tigris & Tiger grouper & Large piscivore & 2.23 & 3.52 & -3.86 & 2.69 & 35.56 & 11.84 & 9 \\
\hline Neoniphon marianus & Longjaw squirrelfish & Large mixed carnivore & -1.57 & 1.42 & -0.14 & 1.09 & 15.71 & 0.00 & 7 \\
\hline Ocyurus chrysurus & Yellowtail snapper & Large mixed carnivore & 5.20 & 3.14 & 4.42 & 2.40 & 27.03 & 5.65 & 96 \\
\hline Opistognathus aurifrons & Yellowhead jawfish & Small mixed carnivore & 5.07 & 1.11 & 1.27 & 0.85 & 9.62 & 1.39 & 13 \\
\hline Pomocanthus arcuatus & Gray angelfish & Large omnivore & 1.56 & 3.74 & 0.89 & 2.85 & 22.50 & 4.95 & 26 \\
\hline Priolepis hipoliti & Rusty goby & Small omnivore & -0.56 & 0.68 & 0.07 & 0.52 & 2.50 & 0.58 & 4 \\
\hline Pseudupeneus maculatus & Spotted goatfish & Small mixed carnivore & 5.15 & 1.79 & 1.45 & 1.37 & 14.55 & 3.75 & 22 \\
\hline Pterois volitans & Lionfish & Small piscivore & 2.28 & 1.85 & -0.31 & 1.41 & 20.00 & 7.07 & 4 \\
\hline Sardinella aurita & Bluesides & Planktivore & -0.69 & 0.66 & -1.39 & 0.51 & 2.65 & 0.68 & 54 \\
\hline Sargocentron coruscum & Reef squirrelfish & Small mixed carnivore & -0.77 & 1.48 & 2.36 & 1.13 & 8.33 & 2.89 & 3 \\
\hline Sargocentron vexillarium & Dusky squirrelfish & Small mixed carnivore & -1.17 & 0.90 & -1.34 & 0.68 & 10.00 & 0.00 & 1 \\
\hline Scarus coeruleus & Blue parrotfish & Large herbivore & 2.05 & 2.31 & 0.69 & 1.76 & 30.00 & 0.00 & 2 \\
\hline Scarus iserti & Striped parrotfish & Small herbivore & 0.67 & 0.63 & 1.11 & 0.48 & 10.28 & 7.04 & 633 \\
\hline Scarus taeniopterus & Princess parrotfish & Small herbivore & -0.99 & 1.25 & 0.02 & 0.96 & 5.78 & 4.70 & 239 \\
\hline Scarus vetula & Queen parrotfish & Large herbivore & -1.37 & 1.68 & -2.34 & 1.28 & 18.78 & 7.70 & 45 \\
\hline Scomberomorus regalis & Cero & Large piscivore & 0.07 & 0.06 & -0.07 & 0.05 & 41.67 & 2.89 & 3 \\
\hline Serranus tabacarius & Tobaccofish & Small mixed carnivore & 0.00 & 1.76 & -1.53 & 1.34 & 6.50 & 4.04 & 4 \\
\hline Serranus tigrinus & Harlequin bass & Small mixed carnivore & -1.07 & 1.58 & 1.31 & 1.20 & 9.00 & 4.14 & 56 \\
\hline Sparisoma atomarium & Greenblotch parrotfish & Small herbivore & 0.13 & 1.53 & -0.16 & 1.17 & 7.77 & 3.28 & 35 \\
\hline Sparisoma aurofrenatum & Redband parrotfish & Small herbivore & 0.02 & 0.65 & -0.08 & 0.50 & 9.37 & 7.54 & 488 \\
\hline Sparisoma chrysopterum & Redtail parrotfish & Large herbivore & 0.31 & 2.90 & 2.00 & 2.21 & 20.00 & 5.92 & 11 \\
\hline Sparisoma viride & Stoplight parrotfish & Large herbivore & 1.39 & 0.40 & -0.41 & 0.30 & 11.22 & 10.33 & 325 \\
\hline Sphyraena barracuda & Great barracuda & Large piscivore & 3.15 & 4.15 & -4.03 & 3.17 & 78.75 & 34.52 & 12 \\
\hline Stegastes adustus & Dusky damselfish & Large omnivore & -0.25 & 0.17 & 0.07 & 0.13 & 10.00 & 0.00 & 12 \\
\hline Stegastes diencaeus & Longfin damselfish & Large omnivore & 3.69 & 0.72 & -1.58 & 0.55 & 9.03 & 2.66 & 102 \\
\hline Stegastes leucostictus & Beaugregory & Large omnivore & 0.10 & 1.63 & 0.02 & 1.25 & 5.54 & 3.88 & 76 \\
\hline Stegastes partitus & Bicolored damselfish & Planktivore & 2.52 & 1.27 & 0.44 & 0.97 & 6.27 & 3.06 & 271 \\
\hline Stegastes planifrons & Threespot damselfish & Large omnivore & -1.64 & 1.73 & 1.56 & 1.32 & 7.78 & 3.27 & 130 \\
\hline Stegastes variabilis & Cocoa damselfish & Large omnivore & 0.39 & 1.60 & 1.58 & 1.22 & 6.71 & 3.84 & 148 \\
\hline Synodus saurus & Bluestriped lizardfish & Small piscivore & -1.43 & 1.05 & -0.35 & 0.80 & 7.50 & 3.54 & 2 \\
\hline Thalassoma bifasciatum & Bluehead wrasse & Planktivore & 0.17 & 0.54 & 0.17 & 0.41 & 5.99 & 3.70 & 1395 \\
\hline Urolophus jamaicensis & Yellow stingray & Large mixed carnivore & 1.86 & 1.43 & 2.13 & 1.09 & 32.50 & 3.54 & 2 \\
\hline
\end{tabular}

